\title{
Liturgie du corps
}

\author{
Claudine Bertrand
}

In "Liturgy of the Body," Bertrand appropriates for women familiar Catholic images and symbols which are usually used in connection with men. She also turns the liturgy into a highly sexually-charged discourse, a discourse which conflicts with that of the "Catholic" liturgy. Bertrand's woman subject is still in the position of sacrificed, but instead of focussing on the word at a spiritual level, as in traditional liturgy, she yokes the word to the body, to that which is gendered "feminine" in the discourses of Catholicism. The liturgy becomes one of women's bodily experiences.

\author{
Son corps \\ Greffé à l'arbre de vie \\ Feu ardent \\ Autel initiatique \\ Colonnes de temple \\ Rituels \\ Cantiques \\ Chants païens
}


Gerbes d'étincelles

Battements du ciel

Un coeur fragile

S'émeut

Encore

Au calice de ses lèvres

Boire l'impalpable

Prière des sens

Ferveur mystique

Frémissement de la poitrine

Muscles et poils

Soudés à la peau

Son corps si brûlant

Offert en sacrifice

Se fait nourriture

Nouvelle alliance 
Corps papier-bible

Au paradis nommé désir

Sans cesse s'immole

Tel le sacrement de la Chair

L'outrance de sa peau

Implore mon regard

En travers de la joue

Des larmes

Couvrent le ciel

$\mathrm{Ne}$ cache pas ta lumière

$\mathrm{Ne}$ sois pas sourd

À mes appels

Ne cache pas ton trésor

À l'entrebâillement

Des cuisses

Corps livré

Au sanctuaire doré

La femme couchée en travers

Réentame la liturgie des gestes

La croix sur la poitrine 
Elle entre avec le présent Pour le jour de la célébration Elle caresse

Sa peau mouillée D'intimité

Femme prostrée en elle-même Enfermée dans son secret Éprouve un choc vibrant

Une veuve sacrée

Communiant aux paroles

Du grand prophète «Ceci est mon corps»

«Ceci est mon sang»

Elle relève la tête Aveuglée

Par l'action sacrificielle De la déchirure du monde Qui sans cesse se voile Fissurée à l'infini 